\title{
Effect of different fractions of seminal plasma on the fertilizing ability of fowl spermatozoa stored in vitro
}

\author{
E. Blesbois and M. de Reviers \\ Station de Recherches Avicoles, INRA, F-37380 Nouzilly, France
}

\begin{abstract}
Summary. This paper describes the effects of whole seminal plasma and of dialysed seminal plasma on the fertilizing ability of fowl spermatozoa stored for $24 \mathrm{~h}$ at $4^{\circ} \mathrm{C}$. The fertilizing ability of fowl semen diluted 1:1 with Beltsville Poultry Semen Extender and stored for $24 \mathrm{~h}$ at $4^{\circ} \mathrm{C}$ was enhanced after replacement of the homologous seminal plasma by the diluent ( 89 versus $77 \%$ fertilization rate). Better results were obtained with seminal plasma dialysed against water before sperm storage to discard the $<1 \mathrm{kDa}$ or the $<50 \mathrm{kDa}$ fractions. It was concluded that low molecular weight seminal plasma fractions could damage the fertilizing ability of spermatozoa during storage at $4^{\circ} \mathrm{C}$, whereas high molecular weight fractions appeared to enhance fertilizing ability.

Ke'words: seminal plasma; fertilizing ability; fowl
\end{abstract}

\section{Introduction}

During short-term in vitro preservation, fowl semen is generally stored at $2-5^{\circ} \mathrm{C}$ after dilution with an artificial diluent. Using whole semen uncontaminated with the transparent fluid exuded from the lymph folds of the cloaca during ejaculation, Lake \& Ravie (1979) and Van Wambeke (1984) obtained high fertilization rates $(87-97 \%$ ) after artificial insemination of hens with semen stored for $24 \mathrm{~h}$ at $4^{\circ} \mathrm{C}$. In contrast, Blesbois (1986) and Sexton (1988) found that the fertilizing ability of fowl spermatozoa stored for $24 \mathrm{~h}$ at $4^{\circ} \mathrm{C}$ is impaired by the presence of seminal plasma. This occurs even if the transparent fluid is absent from the medium (Blesbois, 1986).

Preliminary results from our laboratory indicated that fresh semen diluted 1:1 in seminal plasma uncontaminated by the transparent fluid and inseminated within $30 \mathrm{~min}$ after the semen was collected, gave fertilization rates as high as those from semen diluted 1:1 in Beltsville Poultry Semen Extender (BPSE, Sexton, 1977). After semen was stored for $4 \mathrm{~h}$ at $4^{\circ} \mathrm{C}$, the fertilization rates obtained with semen diluted in seminal plasma were $50 \%$ lower, whereas those obtained with semen diluted in BPSE were similar to those obtained with unstored semen.

The deleterious effects of seminal plasma may result from the accumulation of metabolic wastes (Riddle, 1968; Fujihara \& Howarth, 1978). To prevent the accumulation of toxic metabolic products, Graham \& Shangren (1986) dialysed whole semen during storage but could not retain the fertilizing ability of fowl spermatozoa. The purpose of the present paper was to determine whether the dialysis of seminal plasma only before storage could improve the fertilizing ability of spermatozoa stored for $24 \mathrm{~h}$ at $4^{\circ} \mathrm{C}$ with dialysed seminal plasma and a diluent.

\section{Materials and Methods}

\section{Animals}

Each experiment was conducted with 48 meat-type cockerels from ISA I 99 which was originally derived from a Cornish strain for the males and 300 ISA Vedette for the females. The birds used were between 30 and 80 weeks old. They were housed in individual battery cages. The lighting regimen was $14 \mathrm{~h}$ light: $10 \mathrm{~h}$ dark. All birds were fed the 
same standard diet ( $11.7 \mathrm{MJ}$ of metabolizable energy and $150 \mathrm{~g}$ crude protein per $\mathrm{kg}$ ) in restricted amounts, i.e. $110 \mathrm{~g}$ per male and $120 \mathrm{~g}$ per female once a day to prevent excessive fattening of the birds.

\section{Experimental design}

Experiment 1. Breeders were force-moulted at 45 weeks of age and used for inseminations at the age of 75-80 weeks, i.e. at the peak of their second production period (laying rate $75 \%$ ). The semen was used either fresh (undiluted or diluted) or stored for $24 \mathrm{~h}$ at $4^{\circ} \mathrm{C}$ after dilution.

The following three dilution treatments were applied. In the first treatment, semen was diluted 1:1 in Beltsville Poultry Semen Extender (BPSE, Sexton, 1977). In the second treatment, seminal plasma was replaced by BPSE (centrifuged for $10 \mathrm{~min}$ at $500 \mathrm{~g}$ ) before dilution 1:1 in BPSE. For the third treatment, homologous seminal plasma was replaced by dialysed seminal plasma (see below) and diluted 1:1 in BPSE. During storage the pressure of oxygen of semen samples was $400 \mathrm{nmol} \mathrm{O}_{2} \mathrm{ml}^{-1}$ as measured with a Clarke's electrode (Rank Brothers, Cambridge, UK).

Experiment 2. Breeders were $30-40$ weeks old and their mean laying rate was $75 \%$. They were inseminated either with fresh undiluted semen or with semen stored for $24 \mathrm{~h}$ at $4^{\circ} \mathrm{C}$ after dilution as follows: (i) dilution 1:1 with BPSE; (ii) centrifugation, resuspension of spermatozoa in BPSE up to the initial volume of semen followed by dilution 1:1 of this reconstituted semen in BPSE; (iii) as above, but the resuspension of spermatozoa was done in homologous dialysed seminal plasma (see below) with low molecular weight fractions removed ( $\leqslant 1 \mathrm{kDa}$ ); (iv) as above, low and mean molecular weight fractions ( $\leqslant 50 \mathrm{kDa}$ ) were removed from the homologous dialysed seminal plasma.

Semen collection. Semen was collected by massage (Burrows \& Quinn, 1937). Care was taken to avoid any contamination of semen with the cloacal products and particularly with the transparent fluid. The presence of glucose in the ejaculate indicates contamination of semen by the transparent fluid (Lake, 1966). Glucose determination was therefore systematically performed on all samples (glucose analyser 2, Beckman, Palo Alto, CA, USA) so that any sample containing transparent fluid could be discarded. Ejaculates from 10-12 birds were mixed in the same collection tube, and constituted a 'pool'. Collection and mixing of these 10-12 ejaculates took about 5 min. The spermatozoa concentration of each 'pool' was evaluated using a calibrated photometer $(\lambda=535 \mathrm{~nm})$ and was found to be 5-7 $\times 10^{9}$ spermatozoa per $\mathrm{ml}$.

\section{Preparation of seminal plasma}

Centrifugation. Seminal plasma was separated from spermatozoa by three successive centrifugations. The first centrifugation was performed within $10 \mathrm{~min}$ after semen collection, at $500 \mathrm{~g}$ and $20^{\circ} \mathrm{C}$ for $10 \mathrm{~min}$. The supernatant was then centrifuged again under the same conditions, giving a second supernatant which was centrifuged at $3000 \mathrm{~g}$ and $4^{\circ} \mathrm{C}$ for $30 \mathrm{~min}$. The final supernatant was defined as 'centrifuged seminal plasma'.

Dialysis. The centrifuged seminal plasma was then dialysed for $24 \mathrm{~h}$ at $4^{\circ} \mathrm{C}$ against double distilled water. Three types of membrane were used, type 1 for Expt 1 and types 2 and 3 for Expt 2 ('Poly-Labo'-BP36, 67023 Strasbourg Cedex, France). Type 1 was a 'Visking tube' with an approximate mean pore diameter of $240 \mathrm{~nm}$ allowing salts and the smallest molecules to be eliminated. Types 2 and 3 were more precisely calibrated membranes (Spectrapor 6 ) that can eliminate molecules of less than $1 \mathrm{kDa}$ (type 2) or $50 \mathrm{kDa}$ (type 3). After dialysis, the volume of seminal plasma was $20 \%$ above its original volume following the absorption of water through the membrane. The osmolarity of the

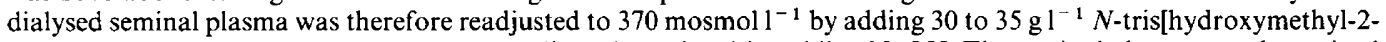
aminoethane]sulphonic acid (TES). $\mathrm{pH}$ was adjusted to $7 \cdot 2-7 \cdot 3$ by adding $\mathrm{NaOH}$. The seminal plasma was then mixed with the centrifuged sperm until the initial semen volume was obtained. This reconstituted semen was then diluted 1:1 with BPSE before being stored at $4^{\circ} \mathrm{C}$.

\section{Artificial inseminations}

The fertilizing ability of semen was evaluated after intravaginal artificial inseminations of 24 hens per treatment. Every hen was inseminated weekly for 5 to 7 weeks using $200 \times 10^{6}$ spermatozoa per dose. Eggs were collected on days 2 to 8 inclusive after each insemination (500 to 1200 eggs per treatment in each experiment). The fertility (fertilized eggs/incubated eggs $\times 100$ ) was determined by candling the eggs 7 days after the incubation started. The hatchability (hatched eggs/fertilized eggs $\times 100$ ) was determined after 21 days of incubation. Fertility and hatchability were compared using $\chi^{2}$ tests (for review see Dagnelie, 1975).

\section{Results}

\section{Experiment 1. Storage of spermatozoa without seminal plasma or with dialysed seminal plasma}

After artificial insemination (Table 1) with fresh undiluted semen, the fertility of eggs was very high $(95.5 \%)$. This rate was reduced when semen was diluted with BPSE $(90 \%, P<0 \cdot 05)$. But this 
reduction did not occur when the seminal plasma was eliminated or replaced by dialysed seminal plasma before dilution ( 95 or $94 \%$, respectively, of fertilized eggs). The adverse effect of BPSE upon recently ejaculated sperm therefore probably results from an interaction between this diluent and some dialysable components of the seminal plasma.

Table 1. Effect of the presence or absence of whole or dialysed seminal plasma in the storage medium on the fertilizing rates of eggs laid 2 to 9 days after artificial insemination with fowl spermatozoa stored for $24 \mathrm{~h}$ at $4^{\circ} \mathrm{C}$ in BPSE* diluent

\begin{tabular}{|c|c|c|c|c|}
\hline \multirow[b]{2}{*}{ Treatment of semen } & \multicolumn{2}{|c|}{ Fresh semen } & \multicolumn{2}{|c|}{$\begin{array}{c}\text { Spermatozoa } \\
\text { stored for } 24 \mathrm{~h} \text { at } 4^{\circ} \mathrm{C}\end{array}$} \\
\hline & Fertility & $\begin{array}{l}\text { Fertilized eggs: } \\
\text { incubated eggs }\end{array}$ & Fertility & $\begin{array}{l}\text { Fertilized eggs: } \\
\text { incubated eggs }\end{array}$ \\
\hline Undiluted & $95 \cdot 5^{\mathrm{a}}$ & $600: 628$ & & \\
\hline Diluted $1: 1$ with BPSE & $90^{\mathrm{b}}$ & $508: 565$ & $72^{\mathrm{d}}$ & $411: 569$ \\
\hline $\begin{array}{l}\text { Seminal plasma replaced by BPSE before } \\
\text { dilution }\end{array}$ & $95^{\mathrm{a}}$ & $545: 572$ & $79^{c}$ & $498: 631$ \\
\hline $\begin{array}{l}\text { Seminal plasma replaced by dialysed } \\
\text { seminal plasma before dilution in } \\
\text { hypertonic BPSE }\end{array}$ & $94^{\mathrm{ab}}$ & $543: 579$ & $81^{c}$ & $541: 667$ \\
\hline
\end{tabular}

Values with the same superscript did not differ significantly $(P<0.05) .{ }^{*}$ BPSE: Beltsville Poultry Semen Extender.

However, after $24 \mathrm{~h}$ of in vitro storage at $4^{\circ} \mathrm{C}$, the fertility of diluted semen was reduced in all treatments. This fall was less marked when the seminal plasma was eliminated and replaced by BPSE alone or by dialysate + BPSE ( 79 or $81 \%$ of fertilized eggs, respectively) than when seminal plasma was still present ( $72 \%$ fertilized eggs). This results from a detrimental effect of seminal plasma on stored sperm.

\section{Experiment 2. Seminal plasma dialysed at 1 or $50 \mathrm{kDa}$}

As in Expt 1, the fertility (Table 2) was high when hens were inseminated with fresh undiluted semen $(93.5 \%)$ and lower when whole semen was diluted with BPSE and stored for $24 \mathrm{~h}(77 \cdot 5 \%)$. The replacement of seminal plasma by BPSE alone before storage still improved the fertilizing ability of sperm stored for $24 \mathrm{~h}$ (fertility: $89 \%$ ). However, the highest fertilizing ability of stored spermatozoa was obtained when the original seminal plasma had been replaced by dialysed seminal plasma plus BPSE. The elimination of the seminal plasma fraction below 1 or $50 \mathrm{kDa}$ before sperm storage resulted in 92 or $93 \%$, respectively, of fertilized eggs, i.e. very near the percentage of fertilized eggs obtained with fresh undiluted semen in this experiment. The dialysis of seminal plasma before storage can therefore prevent the spermatozoa from losing their fertilizing ability.

The results obtained after storage were higher than in Expt 1 (77.7-89 versus $72-79 \%)$. This may result from the use of younger birds ( $30-40$ weeks old) than in Expt 1 (75-80 weeks old), although the hens were used just after the laying peak in each case.

\section{Discussion}

The results presented here show that the seminal plasma and the interaction between the seminal plasma and the diluent influence the fertilizing ability of fresh and stored semen. According to Sexton (1977) and Blesbois (1986), the dilution of whole semen (spermatozoa plus seminal plasma) with an artificial diluent impairs the fertilizing ability of fresh semen. In addition, if spermatozoa are resuspended in the artificial diluent after the elimination of seminal plasma, the fertility is as high as the fertility obtained with fresh undiluted semen. These last two observations show that the 
Table 2. Effects of seminal plasma dialysed at $1 \mathrm{kDa}$ or $50 \mathrm{kDa}$ on fertilization rates of eggs obtained $2-9$ days after artificial insemination with fowl spermatozoa stored for $24 \mathrm{~h}$ at $4^{\circ} \mathrm{C}$ diluted 1:1 in BPSE* diluent

\begin{tabular}{lcc}
\hline & Fertility & $\begin{array}{c}\text { Fertilized eggs: } \\
\text { incubated eggs }\end{array}$ \\
\hline $\begin{array}{l}\text { Fresh undiluted semen } \\
\text { Semen stored for 24 } \mathrm{h} \text { at } 4^{\circ} \mathrm{C} \text { diluted } 1: 1 \text { in BPSE: }\end{array}$ & $93 \cdot 5^{\mathrm{a}}$ & $1075: 1147$ \\
whole semen diluted with BPSE & $77 \cdot 5^{\mathrm{c}}$ & $873: 1128$ \\
seminal plasma replaced by BPSE before dilution & $88^{\mathrm{b}}$ & $970: 1104$ \\
seminal plasma replaced by seminal plasma dialysed at $1 \mathrm{kDa}$ & $92^{\mathrm{a}}$ & $982: 1070$ \\
before dilution in hypertonic BPSE & $93^{\mathrm{a}}$ & $992: 1067$ \\
seminal plasma replaced by seminal plasma dialysed at $50 \mathrm{kDa}$ & & \\
\hline before dilution in hypertonic BPSE & & \\
\hline
\end{tabular}

Values with the same superscript did not differ significantly $(P<0 \cdot 05)$. ${ }^{*}$ BPSE: Beltsville Poultry Semen Extender.

artificial diluent alone is not responsible for the decrease in fertility. The interaction between seminal plasma and the artifical diluent is responsible for the deleterious action of dilution on fresh semen.

The results obtained with stored semen clearly demonstrate that seminal plasma has a deleterious effect on spermatozoa stored in vitro.

Dialysis of seminal plasma before storage indicates that the deleterious effect results from the dialysable fraction of seminal plasma (molecular weight $<1000$ ). This may be related to the presence in seminal plasma of toxic factors such as zinc (Blesbois \& Mauger, 1989) and peroxides (authors' unpublished observations). The use of dialysed seminal plasma improves the fertilizing ability of stored sperm, which seems to indicate that larger molecules in seminal plasma $(>50 \mathrm{kDa})$ may improve the storage of spermatozoa.

\section{Effect of seminal plasma on fresh semen}

The composition of seminal plasma has been used as a basis for the earliest cock semen diluents (Lake, 1960). Seminal plasma has been reported to maintain the fertilizing ability of fresh diluted semen (Munro, 1938; Weakly \& Shaffner, 1952) and especially highly diluted semen (Lake \& Ravie, 1987). Moreover, seminal plasma stimulates the motility and the respiration of fowl spermatozoa (Fewless et al., 1975; Terada \& Watanabe, 1978; Ashizawa \& Wishart, 1987; Wishart \& Ashizawa, 1987). The results of our preliminary experiments and those of Sexton (1988) also indicate that the dilution of fresh semen with seminal plasma at a ratio of $1: 1$ does not change the fertilizing ability of fresh semen.

\section{Effects of seminal plasma on in vitro storage of spermatozoa}

The situation is more confusing for stored semen. Lake \& Ravie (1979) and Van Wambeke $(1967,1984)$ reported high fertility $(89-97 \%)$ for cock semen stored for $24 \mathrm{~h}$ at $2-5^{\circ} \mathrm{C}$ in semen containing homologous seminal plasma and artificial diluents.

The authors attributed their success partly to the lack of transparent fluid in the semen used. Sexton (1988), using seminal plasma containing some transparent fluid, reported a deleterious effect of stored seminal plasma on fresh and stored semen. This effect disappeared after filtration.

Our results were obtained with seminal plasma without any transparent fluid (attested by careful manipulations and glucose concentration). In these conditions, as in previous experiments (Blesbois \& Mauger, 1987, 1989), seminal plasma is toxic to fowl spermatozoa stored for $4 \mathrm{~h}$ and $24 \mathrm{~h}$ at $4^{\circ} \mathrm{C}$.

Most of the other reports on seminal plasma toxicity concern the resistance of spermatozoa to cold shock. Toxic effects of seminal plasma on the motility and morphology of thawed spermatozoa have been reported in many species including the ram (Schmehl et al., 1988) and the bull 
(Garcia \& Graham, 1987a, b, c). In each case, the use of dialysis revealed that the deleterious effect of seminal plasma was located in the low molecular weight seminal plasma fraction $(12-14 \mathrm{kDa}$ for cocks and rams, $1 \mathrm{kDa}$ for bulls).

Results of dialysis were obtained in original conditions since the storage of semen was at $4^{\circ} \mathrm{C}$ and fertility was tested. Results indicate that, in cocks, the deleterious effect of seminal plasma is located in the low molecular weight fraction $(<1 \mathrm{kDa})$ of seminal plasma. Moreover, the fraction of molecular weight higher than 1 or $50 \mathrm{kDa}$ appears to be beneficial to the in vitro storage of fowl spermatozoa. The same tendency has been previously reported by Garcia and Graham (1987c) concerning the resistance of bull semen to freezing. Storage of cock semen with dialysed seminal plasma ( 1 or $50 \mathrm{kDa}$ ) therefore led to fertilization rates as high as those obtained with fresh semen.

In conclusion, the present study emphasizes the complexity of the role of seminal plasma and its duality of effects on the storage of fowl semen. Seminal plasma appears to contain fractions of molecular weight higher than $50 \mathrm{kDa}$ that are beneficial to the in vitro storage of spermatozoa and, in contrast, fractions of molecular weight lower than $1 \mathrm{kDa}$ which are toxic to in vitro storage of spermatozoa.

We thank I. Grasseau for technical assistance, Mrs Rérat for help in the English form of the manuscript, J. Courtemanche and J. M. Meslier for bird management and artificial insemination.

\section{References}

Ashizawa, K. \& Wishart, G.J. (1987) Resolution of the sperm motility stimulating principle of fowl seminal plasma into $\mathrm{Ca}^{++}$and an unidentified low molecular weight factor. Journal of Reproduction and Fertility 81, 495-499.

Blesbois, E. (1986) Effects du plasma séminal sur la conservation à $4^{\circ} \mathrm{C}$ des spermatozoïdes de coq. 7 th European Poultry Conference, Paris 2, pp. 1009-1015.

Blesbois, E. \& Mauger, I. (1987) Effects of ovalbumin on the motility and fertilising ability of fowl spermatozoa stored for 24 h at 4 C. British Poultry Science 28, 483-492.

Blesbois, E. \& Mauger, I. (1989) Zinc content of fowl seminal plasma and its effects on spermatozoa after storage at $4^{\circ} \mathrm{C}$. British Poultry Science 39, 677-685.

Burrows, W.H. \& Quinn, J.R. (1937) The collection of spermatozoa of the domestic fowl and turkey. Poultry Science 16, 19-24.

Dagnelie, P. (1975) Théorie et Méthodes Statistiques Presses agronomiques de Gembloux, ASBL, Belgium.

Fewlass, T.A., Sexton, T.J. \& Shaffner, C.S. (1975) Effect of various levels of egg yolk, milk, seminal plasma or blood serum on the respiration and reproductive efficiency of chicken spermatozoa. Poultry Science $54,346-349$.

Fujihara, N. \& Howarth, Jr, B. (1978) Lipid peroxidation in fowl spermatozoa. Poultry Science 57, 1766-1768.

Garcia, M.A. \& Graham, E.F. (1987a) Effects of lowmolecular-weight fractions from milk, egg yolk and seminal plasma on freezability of bovine spermatozoa. Cryobiology 24, 429-436.

Garcia, M.A. \& Graham, E.F. (1987b) Factors affecting the removal of low molecular weight fraction of bovine spermatozoa. Cryobiology 24, 437-445.

Garcia, M.A. \& Graham, E.F. (1987c) Dialysis of bovine sperm and its effects on fresh and frozen-thawed spermatozoa. Cryobiology 24, 446454.
Graham, E.F. \& Shangren, L.I. (1986) Effect of different treatments on cock semen stored at $5^{\circ} \mathrm{C}$. Scientific Agricultural Sinica 3, 83-89.

Lake, P.E. (1960) Studies on the dilution and storage of fowl semen. Journal of Reproduction and Fertility $\mathbf{1}$, 30-35.

Lake, P.E. (1966) Physiology and biochemistry of poultry semen. Advances in Reproductive Physiology 1, 93-123, Loges Press, London.

Lake, P.E. \& Ravie, O. (1979) Effect on fertility of storing fowl semen for $24 \mathrm{~h}$ at $5^{\circ} \mathrm{C}$ in fluids of different pH. Journal of Reproduction and Fertility 57, 143-155.

Lake, P.E. \& Ravie, O. (1987) Effect on fertility of low numbers of fowl spermatozoa inseminated in aqueous diluent or semen components of the fowl and turkey. British Poultry Science 28, 75-80.

Munro, S.S. (1938) Functional changes in fowl sperm during their passage through the excurrent ducts of the fowl. Journal of Experimental Zoology 79, 71-92.

Riddle, V.M. (1968) Energy metabolism of fowl spermatozoa: evidence for mechanisms and artefacts in Ringer's phosphate buffer. $\mathrm{PhD}$, University of California.

Schmehl, M.K., Anderson, S.P., Vasquez, I.A. \& Graham, E.F. (1986) The effect of dialysis of extended ram semen prior to freezing on post-thaw survival and fertility. Cryobiology 23, 406-414.

Sexton, T.J. (1977) A new poultry semen extender. 2. Effect of the diluent components on the fertilizing ability of chicken semen stored at $4^{\circ} \mathrm{C}$. Poultry Science 97, 277-284.

Sexton, T.J. (1988) Influence of seminal plasma on the fecundity of chicken spermatozoa. Theriogenology 30, 711-720.

Terada, T. \& Watanabe, M. (1978) Effects of seminal plasma on the motility and metabolism of cock 
spermatozoa. Japanese Journal of Zootechnology Science 49, 47-53.

Van Wambeke, F. (1967) The storage of fowl spermatozoa. 1. Preliminary results with new diluents. Journal of Reproduction and Fertility 13, 571-575.

Van Wambeke, F. (1984) Effect of semen storage time and number of sperm inseminated on the fertility and hatchability of eggs from dwarf broiler breeder hens. Poultry Science 25, 583-587.
Weakley, C.E. \& Shaffner, C.S. (1952) The fertilizing capacity of diluted chicken semen. Poultry Science 31, $650-651$.

Wishart, G.J. \& Ashizawa, K. (1987) Regulation of the motility of fowl spermatozoa by calcium and cAMP. Journal of Reproduction and Fertility 80, 607-611.

Received 21 March 1991 